\title{
A CASE REPORT CASE OF HYDATID CYST.
}

\footnotetext{
1. MBBS, FCPS (Pediatrics)

Senior Registrar

Department of Pediatric Medicine Children Hospital Faisalabad.

2. MBBS, FCPS (Pediatrics)

Senior Registrar

Department of Pediatric Medicine Children Hospital Faisalabad.

3. MBBS, FCPS (Pediatrics)

Assistant Professor

Department of Pediatric Medicine

Children Hospital Faisalabad.
}

Correspondence Address:

Dr. Jaweeria Masood

541-B, Peoples Colony Faisalabad.

jaweriamasood6@gmail.com

Article received on:

09/04/2019

Accepted for publication:

02/06/2019

\section{INTRODUCTION}

Echinococcosis also known as hydatid disease is a zoonotic disease of world-wide distribution caused by Larval stage (metacestode) of the parasite. It belongs to family taenidae \& genus echinococcus. It is transmitted to human through sheep and cattle. Definitive host is dog.

Most common organ involved in hydatid disease in adults are liver $64 \%$ and lungs $10 \%$ but in children this ratio is almost reversed other organs involved are brain, bone and kidney. ${ }^{1,2}$ Pulmonary hydatid disease usually present with chronic cough, dyspnea, chest pain, hemoptysis or patient may present with complications (cyst rupture, secondary infection) owing to this presentation, there is high chance of misdiagnosis and maltreatment. ${ }^{3,4,5}$ Radiology \& serology are principal diagnostic modality usually ultrasound is diagnostic but in complicated \& doubtful cases CT chest is diagnostic. Serological marker are also helpful for diagnosis.

Treatment is pharmacological and surgical.

\section{CASE REPORT}

A 9-year-old Faizan resident of Raza Abad (FSD) admitted through OPD presented initially with complaint of cough \& fever from last one and a half month \& respiratory distress from last three days. Fever was initially low grade and intermittent but from last 10 days it was high grade \& continuous. Cough which was initially dry became productive since then. No history of contact with TB was present CBC with ESR and chest X-Ray was done. CBC showed slightly high TLC (15000) and ESR (108). Sputum for AFB and Mantoux test was found -ve chest X-ray showed consolidation on left side. On the basis of these investigations diagnosis of lobar pneumonia was made. Patient remained admitted in hospital \& received injectable antibiotics for seven days. Patient's fever was settled and cough was improved and was discharged and called for follow up but patient did not come back after 15 days patient again developed fever, cough and streak of blood in sputum for which patient was again admitted this time there was no respiratory distress but history of weight loss was there. No body swelling, jaundice, joint pain, bleeding manifestation, abdominal pain, recurrent chest infection, anorexia.

O/E he was vitally stable, weight was $20 \mathrm{~kg}$ ( $<25$ centile) height was $125 \mathrm{~cm}$ (50 th centile). BCG scar was positive. No other remarkable 
findings in general physical examination. On respiratory system examination patient was having normal chest shape, trachea central, there was decreased chest movement, dull percussion note and reduced vocal resonance and air entry in left lower chest. Other systemic examination was unremarkable considering history \& based on examination findings a diagnosis of left sided para pneumonic affusion was made. So, CBC ē ESR, CXR \& ultrasound chest was carried out. This time CBC was unremarkable, CXR findings were almost same as were previous (Image-1). Ultrasound showed cystic lesions measuring $4.4 \mathrm{x}$ $4.2 \mathrm{~cm}$ ē surrounding area of consolidation having air bronchograms in it. Ultrasound abdomen was also carried out to rule out cyst in other visceras. CT chest ē I/V contrast was advised (Image-2). Echinococcus antibodies were also sent which were found positive. A CT è I/V contrast also confirmed the presence of large pulmonary hydatid cyst $68 \times 60 \times 40 \mathrm{~mm}$. Although this cyst was on left side, but was not causing any pressure symptoms. So patient was put on medical treatment i.e Albendazole ē the dose of $15 \mathrm{mg} /$ $\mathrm{kg} /$ day B.D. Side by side we also took surgical opinion and they also second our management and gave opinion that. There is no need of surgery as there are no pressure symptoms \& we should see response of patient toward treatment. Patient was discharged after ten days and kept on follow up. After three-month patient X-ray finding were improved and ultrasound showed that cyst size was reduced with linear irregular floating shadow which could be floating membrane in transition phase that can be ultimately healed (Image-3) \& after six month of treatment patient was completely healed.

\section{DISCUSSION}

In children lung (64\%) \& liver (28\%) are the most common sites of hydatid cyst. ${ }^{1}$ Right lung involvement is common than the left. Mostly unilateral but in $20 \%$ of cases there is $\mathrm{B} / \mathrm{L}$ involvement. However, our patient had left sided involvement ${ }^{1,7}$

Patients with pulmonary hydatid cyst is usually presented by respiratory symptoms including cough, chest pain hemoptysis, dyspnea, fever or may be presented by the complication symptoms as compression of bronchi intrabronchial rupture. Patient may present $\bar{e}$ signs and symptoms of anaphylaxis shock, when the cyst ruptures. ${ }^{2}$

Due to there multiple presentation, the patients of pulmonary hydatid cyst may be misdiagnosed. As in our case patient was first misdiagnosed as left sided lobar pneumonia.,

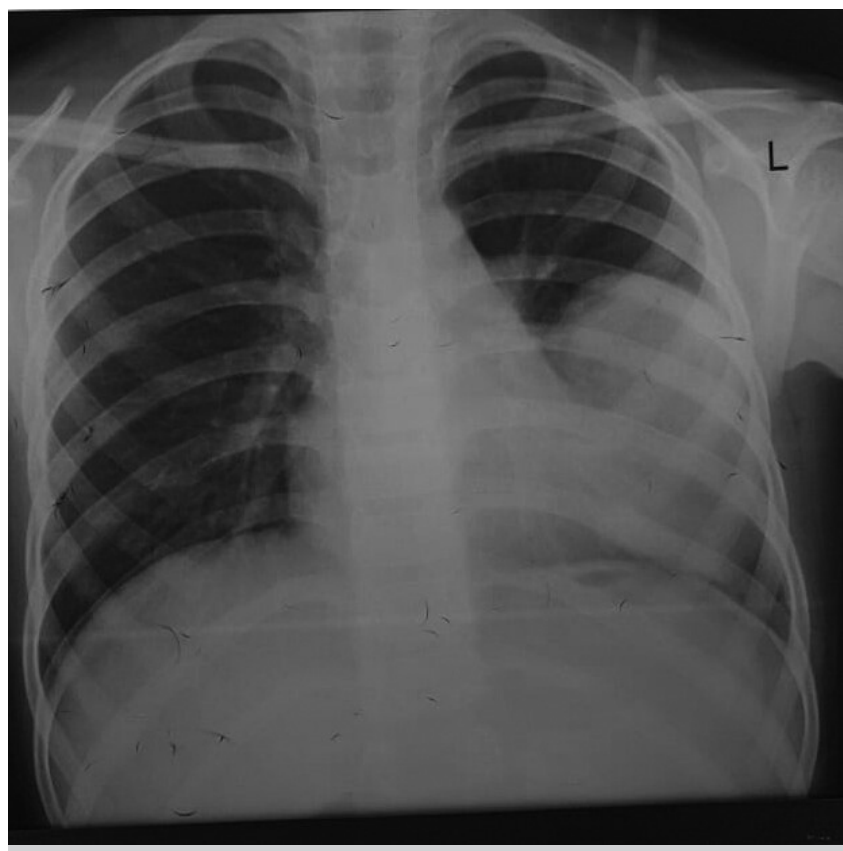

Image-1. Patient X-ray at the time of readmission.

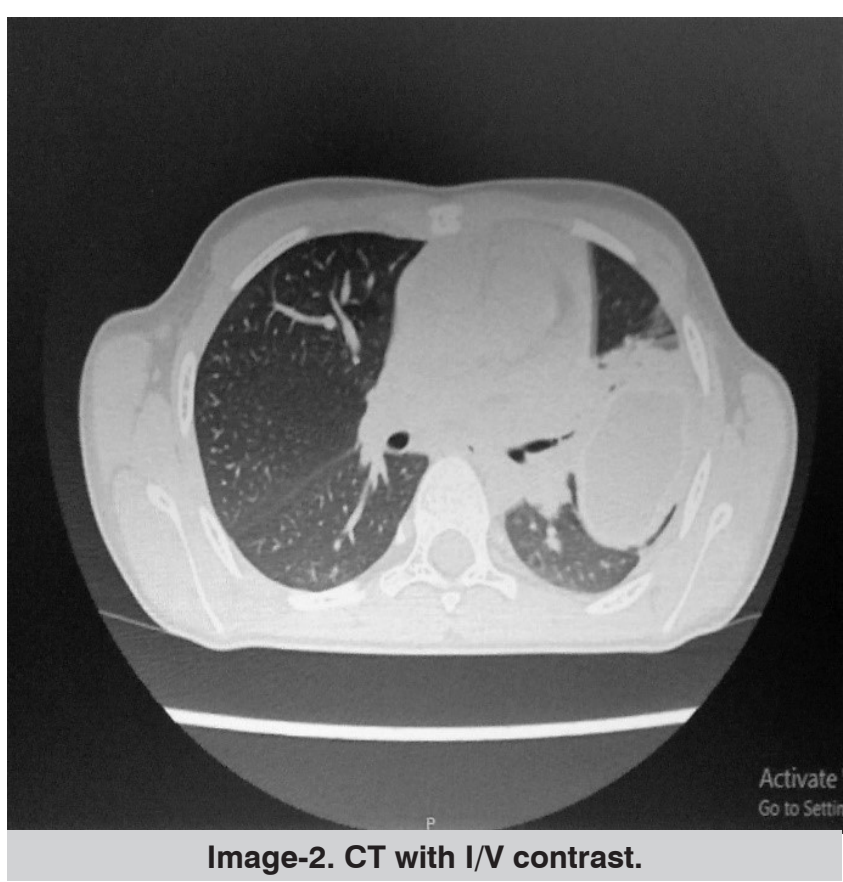




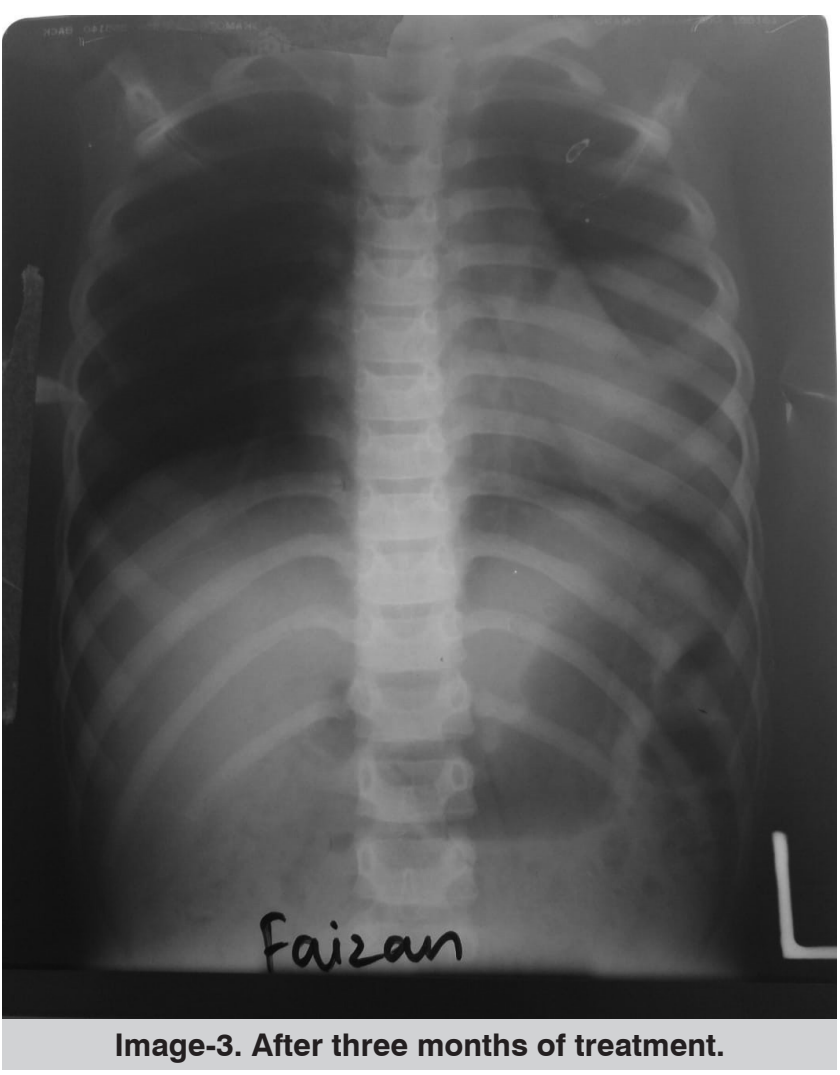

Besides CXR other imaging techniques are important in the diagnosis of pulmonary hydatidosis. Although USG is most valuable tool for the both diagnosis \& treatment of liver hydatid cyst but ultrasound may help in diagnosis of pulmonary hydatid cyst specially for peripherally located cyst to rule out plural involvement CT \& $\mathrm{MRI}$ is done in cases in any confusion. More over CT or MRI is also important in planning surgical intervention. ${ }^{6}$

Serological studies may be useful in confirming a diagnosis of cystic echinococcosis \& include ELISA, indirect hemagglutination, latex agglutination \& immunoblot test. Fiberoptic bronchoscopy is also useful in a typical clinical \& radiological feature. ${ }^{1}$

Medical treatment (Albendazole) is effective if cyst size is smaller than $6 \mathrm{~cm}$ and it is away from any vital structure like heart, main bronchus \& major vessel but surgical intervention is a definitive treatment for hydatid cyst. Resection of cyst can be done with other surgical modalities, lobectomy, wedge resection, pericystectomy \& endocystectomy. Medical treatment is also given while awaiting for surgery \& to prevent spread \& recurrence of disease. ${ }^{4}$

In conclusion, pulmonary echinococcosis can be presented by respiratory symptoms that may be confused è other pulmonary diseases. So, while thinking of common causes of a disease, we must consider rare causes.

Copyright $(02$ June, 2019.

\section{REFERENCES}

1. Sarkar M, Pathania R, Jhobta A, Thakur B, and Chopra R; Cystic pulmonary hydatidosis; Lungindia official organ of Indian chest society, 2016 Mar-Apr; 33(2) 179-191 PMCID, PMC 4797438.

2. R. Philip, M. Miguel, Jr. White A.C: Echinococcus granuloses and echinococcus multilocularis; Nelson Textbook of Paediatrics 20 ${ }^{\text {th }}$ Edition: 1753-1756.

3. Brunetti E, White AC: Cestode infestations: Hydatid disease and cysticercosis, infect Dis Clin North Am 26:421-435, 2012.

4. Stojkovic M, Zwahlen M, Teggi A, etal: Treatment response of cystic echinococcosis to benzimadazoles: A systemic review, PLOS Negl Trop Dis 3: e 524, 2009.

5. Ozdemir A, Bozdemir E, Abbiyik D, Daar G, Korkuts, etal (2015) Anaphylaxis due to ruptured pulmonary hydatid cyst in a 13-year-old boy, Asia Pac Allergy 5; 128-131.

6. Darwish, B. Clinical and radiological manifestation of 206 patients with pulmonary hydatidosis over a 10year period. Prim Care Respir J, 15(4): 246-51. Epub 2006 Jul.

7. R. Morae, C. Feldman. Pulmonary echinococcosis european respiratory $\mathrm{J}$ vol 21(6); 1069-1077; PubMed 127975042003 June. 


\section{CORRECTION}

The amendment of the Professional Vol: 26, No.09 (Prof-4020) titled: "Remarkable effect of topical betamethasone valerate $\mathbf{0 . 1 \%}$ on progress of psoriasis disease" on page $1543-1544$ is as under;

Table-I, Figure-1 \& Table-II missed in the results.

Correction done in online version.

\begin{tabular}{|c|c|c|c|}
\hline \multicolumn{4}{|c|}{ AUTHORSHIP AND CONTRIBUTION DECLARATION } \\
\hline Sr. \# & Author(s) Full Name & Contribution to the paper & Author(s) Signature \\
\hline 1 & Jaweeria Masood & Script Writing. & Jaweeria - \\
\hline 2 & Irum lqbal & References. & \\
\hline 3 & Zahid Mahmood Anjum & References. & $100 d$ \\
\hline
\end{tabular}

